\title{
HOW AN ARRAY OF DISCRETE RESONATORS, COUPLED BY FLUID, CAN REPRODUCE THE DYNAMICS OF CLICK-EVOKED OTOACOUSTIC EMISSIONS

\section{Hero P. Wit ${ }^{A, D-F}$}

\author{
Otolaryngology/Head and Neck Surgery, University of Groningen, University Medical \\ Center Groningen, The Netherlands
}

Corresponding author: Hero P. Wit; Otolaryngology/Head and Neck Surgery, University of Groningen, University Medical Center Groningen, Hanzeplein 1, 9700RB, Groningen, The Netherlands; email: hero.wit@ziggo.nl; Phone: +31 622416704

\begin{abstract}
This paper describes a basic representation of cochlear mechanics. To represent the cochlear partition, we begin with an array of discrete tuned resonators, immersed in fluid. The resonators are stimulated by an impulse from another resonator, which is taken to be the middle ear. A "state space" representation of the classic transmission line model is used to describe the multiple fluid-borne interactions which take place between all the resonators. The overall response seen at the middle ear looks remarkably similar to a click-evoked otoacoustic emission (CEOAE) if the place-frequency map of the cochlea contains tuning irregularities. The paper describes, step by step, how the CEOAEs are generated. We show that impulse responses from each oscillator are transported back to the ear canal, and that these responses add up to create a standing wave pattern in the fluid pressure. This standing wave is the sum of waves repeatedly travelling back and forth between an irregularity and oscillator 1 . If only one irregularity is present, the impulse response of oscillator 1 (the "stimulus") is followed by a weak single oscillation, with the characteristics of a "gammachirp". If irregularities are present all along the cochlear partition, many gammachirps add up to produce a signal with similar characteristics as a CEOAE measured in a normal hearing ear. The model therefore describes the generation of click-evoked otoacoustic emissions.
\end{abstract}

Key words: state space model $\bullet$ gammatone $\bullet$ oscillator array $\bullet$ cochlea $\bullet$ gammachirp $\bullet$ irregularities

\section{JAK ZESPÓŁ DYSKRETNYCH REZONATORÓW POŁĄCZONYCH PŁYNEM MOŻE REPRODUKOWAĆ DYNAMIKĘ EMISJI OTOAKUSTYCZNYCH WYWOŁANYCH TRZASKIEM}

\section{Streszczenie}

Praca opisuje prosty model mechaniki ślimaka. Aby odwzorować przegrodę ślimaka wyszliśmy od zespołu pojedynczo nastrojonych rezonatorów zanurzonych w płynie. Rezonatory są pobudzane impulsem z innego rezonatora, który przedstawia ucho środkowe. Przedstawienie klasycznego modelu transmisji liniowej jako przestrzeni stanów zostało użyte do opisu wielokrotnych przenoszonych w płynie wzajemnych oddziaływań między wszystkimi rezonatorami. Ogólna odpowiedź rejestrowana na uchu środkowym jest niezwykle podobna do emisji otoakustycznej wywołanej trzaskiem (CEOAE), jeżeli mapa rozmieszczenia częstotliwości w ślimaku obejmuje nieregularności strojenia. $\mathrm{W}$ tej pracy opisujemy krok po kroku jak generowane są CEOAE. Pokazujemy, że odpowiedzi na impulsy z każdego oscylatora są przekazywane wstecznie do kanału słuchowego i że odpowiedzi te sumują się, aby stworzyć wzór fali stojącej ciśnienia płynu. Ta fala stojąca jest sumą fal przemieszczających się pomiędzy miejscem wystąpienia nieprawidłowości a oscylatorem 1. Jeżeli występuje tylko jedna nieregularność, po impulsie z oscylatora 1 („bodźcu”) następuje słaba pojedyncza oscylacja typu „gammachirp”. Jeżeli wzdłuż całej przegrody ślimaka występują nieregularności, wiele tonów typu „gammachirp” sumuje się i powstaje sygnał o charakterystyce zbliżonej do CEOAE mierzonych w normalnie słyszącym uchu. Oznacza to, że model dobrze opisuje powstawanie emisji otoakustycznych wywołanych trzaskiem.

Słowa kluczowe: model przestrzeni stanów • ton gamma • zespół oscylatorów • ślimak • gammachirp • nieregularności

\section{Introduction}

Otoacoustic emissions (OAEs) are weak sounds emitted by the inner ear which were discovered by Kemp more than 40 years ago $[1,2]$. His startling discovery was soon confirmed by others [3-7]. Probst et al. [8] has given a good review of the different classes of OAEs and their properties.

One of these classes are click-evoked otoacoustic emissions (CEOAEs) which, almost right after their discovery, became widely used clinically to test the integrity of the human cochlea, especially in newborns [9]. Many characteristics of CEOAEs were investigated in early studies (see for instance the 1980 paper by Kemp and Chum [10]). One of these characteristics is that a CEOAE shows the typical pattern as shown in Figure 1A: lower frequency components appear later along the time axis. A rough estimate is that the delay after stimulus onset for a particular frequency component is about 10 periods $[2,4]$. The frequency spectrum of a CEOAE shows a peaked structure (Figure 1B), and no two ears produce exactly the same CEOAE pattern [11]. 

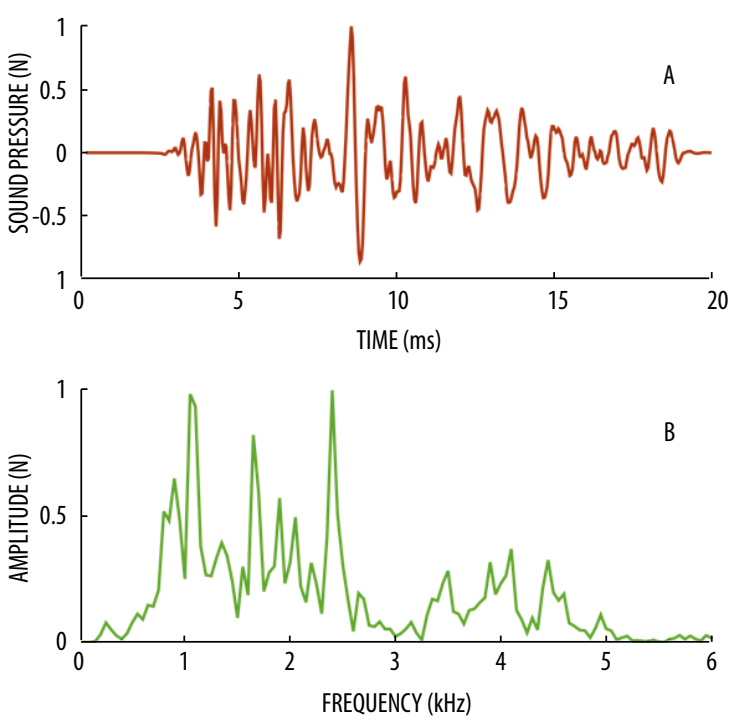

Figure 1. A. Click-evoked otoacoustic emission (CEOAE), measured in the ear of a normal hearing adult with the Otodynamics ILO v6 equipment in a clinical setting. The first $3 \mathrm{~ms}$ of the response is truncated to remove the much stronger stimulus. B. Amplitude spectrum for the signal in A

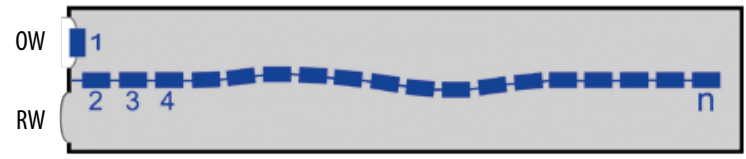

Figure 2. Blue rectangles numbered 2 to $n$ : array of oscillators in a fluid-filled box, representing the human cochlea. Oscillator 1 represents the whole middle ear, including the ear drum and ossicles. OW: oval window; RW: round window

The spectrum shown in Figure 1B shows a more or less regular pattern (equal distances between the peaks). To explain this periodicity, that can be seen many times in CEOAE spectra, Zweig and Shera [12] proposed the presence of random irregularities in the micromechanics of the organ of Corti. This concept inspired the present author decades ago [13] to synthesise CEOAEs by adding together 256 fourth-order gammatones. The frequencies of the gammatones were generated by multiplying each number in a regular array, which increased exponentially from 0.5 to $5 \mathrm{kHz}$, with $1+0.02 \eta_{\mathrm{i}}$ (where the random numbers $\eta_{i}$ come from a normal distribution with mean 0 and standard deviation 1). Irregularities were necessary to generate realistically looking CEOAEs. For all $\eta_{\mathrm{i}}$ being 0 , the gammatones cancel each other except at the edges of the array [14].

In this respect it should be noted that Gold, the predictor of spontaneous otoacoustic emissions [15], stated at a congress in 1988 that individual fibers in the inner ear would all cancel their outputs if they were neatly overlapping, and that therefore inaccuracies in the system are necessary to produce evoked sound [16]. A few years earlier Sutton and Wilson [17] had already proposed a model in which emissions were caused by irregularities in cochlear frequency mapping. However, the essential difference between the model of Sutton and Wilson and the approach used here is that these authors introduced only a few localised irregularities, while in the present paper irregularities are inserted all along the cochlear partition.

"Simply" adding gammatones to synthesise a CEOAE supposes three things: 1) that the click stimulus generates gammatone-like vibrations all along the cochlear partition; 2) that there is no onset delay for these vibrations; and 3) that all vibrations are transported back to the ear canal, also without delay.

The present paper also incorporates the concept of random irregularities, but it follows a less direct approach to calculate how CEOAEs are generated. In essence, it investigates the properties of an array of harmonic oscillators embedded in fluid, as in the classical transmission line model for the mammalian cochlea $[18,19]$. A valuable aspect of this approach is that it makes clear three aspects that are not covered in the "sum of gammatones" approach: the transport of the stimulating click from the middle ear to an individual oscillator, the coupling back of the vibration of the oscillators to the middle ear, and the coupling between the oscillators, which influences their behaviour.

The paper concentrates on, and describes in detail, what is minimally needed to obtain CEOAEs with realistic properties. It is, in fact, the basal part of more extensive models, like for instance that of Moleti et al. [20].

We start with the description of the model with no irregularities included. This is followed by an investigation of its behaviour when stimulated with a continuous sine wave or with a click. The next step is the introduction of a single irregularity in the array of natural frequencies of the oscillators. Finally, irregularities are incorporated all along the oscillator array. A mathematical basis of the model and its properties can be found in three appendices.

Calculations were done with Mathematica and are partly based on the compact "state space" formulation [21].

\section{The model}

The human cochlea is represented by a one-dimensional array of $n-1$ harmonic oscillators immersed in fluid in a rigid-walled box (Figure 2).

It is supposed that the coupling between the oscillators is only through the fluid. The fluid pressure that is exerted on an individual oscillator will obey the same relations as in the state space model of Elliott et al. [22-24] (details are given in Appendix 1).

The equation to be solved for the time course of displacement $x_{j}(t)$ of the $j$-th oscillator in the array is the wellknown differential equation for a damped harmonic oscillator driven by an external force:

$\ddot{x}_{\mathrm{j}}(t)+\gamma_{\mathrm{j}} \omega_{\mathrm{j}} \dot{x}_{\mathrm{j}}(t)+\omega_{\mathrm{j}}^{2} x_{\mathrm{j}}(t)=\kappa \mathrm{p}_{\mathrm{j}}(t)$, 

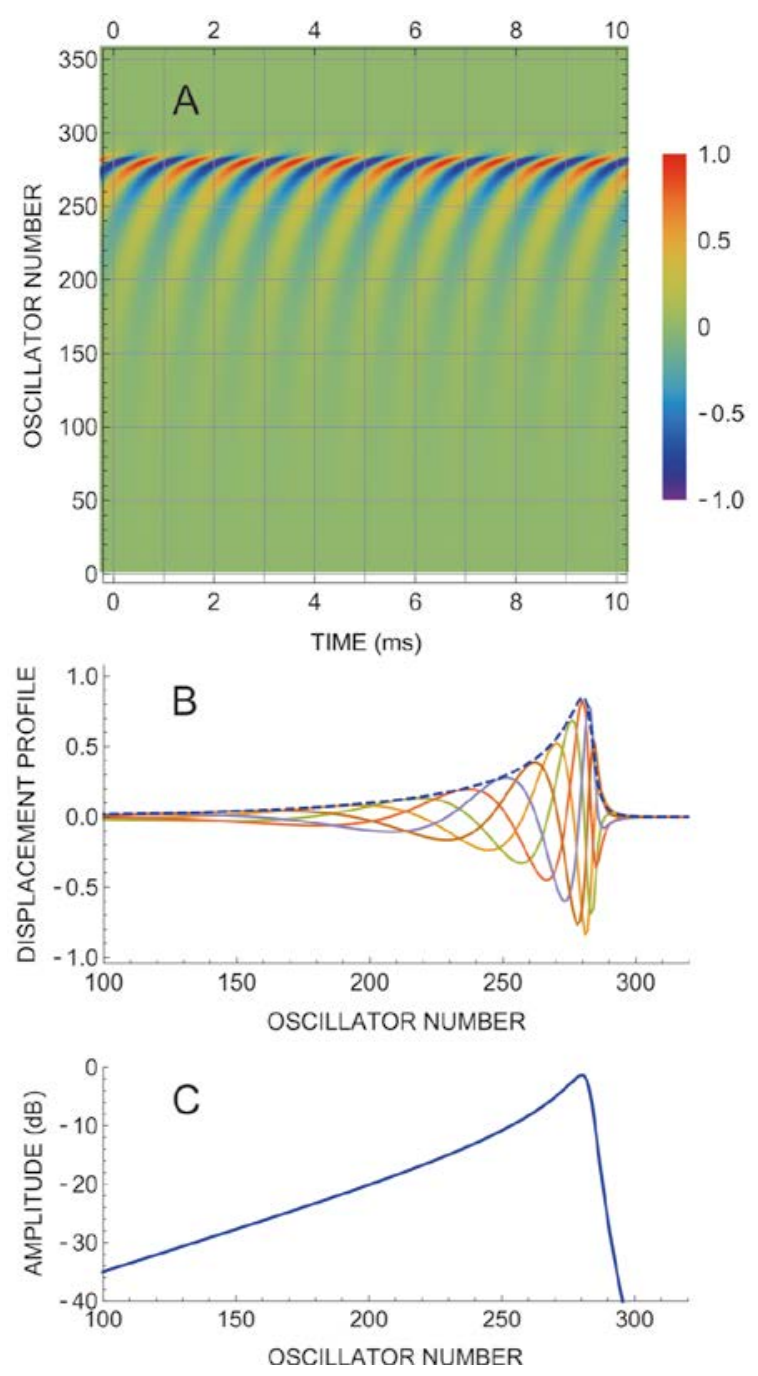

Figure 3. A. Density plot for displacement as a function of time for oscillators 2 to 350 . The colour bar gives displacement, divided by maximum displacement in the array. B. Successive displacement profiles along the array during one period of the oscillation. The dashed line marks the amplitude (maximum displacement) as a function of oscillator number. C. Dashed line in B, with amplitude scale in $\mathrm{dB}$

with $\gamma_{j}$ being the damping factor, $\omega_{j}$ the natural angular frequency, and $p_{\mathrm{j}}(t)$ the fluid pressure acting on the $j$-th oscillator ( $\kappa$ is a constant with value 1 and dimension $\mathrm{m}^{2} / \mathrm{kg}$ to give both sides of the equation the dimension of an acceleration). Equation 1 is the same as that for the oscillatory behaviour of the cochlear partitions in the "statespace example.m" Matlab-file (a supplement of [24]). All following results are for a set of $n=501$ coupled differential equations.

\section{Sine wave stimulus}

A continuous sine wave with frequency $1 \mathrm{kHz}$ (the natural frequency of oscillator 284) was added to the right-hand term $\mathrm{\kappa p}_{1}(t)$ of the differential equation for oscillator 1 , and the set of $n=501$ equations was solved with Mathematica's NDSolve routine, for a total time of $40 \mathrm{~ms}$ and a time step of $5 \mu$ s. All oscillators started with displacement and
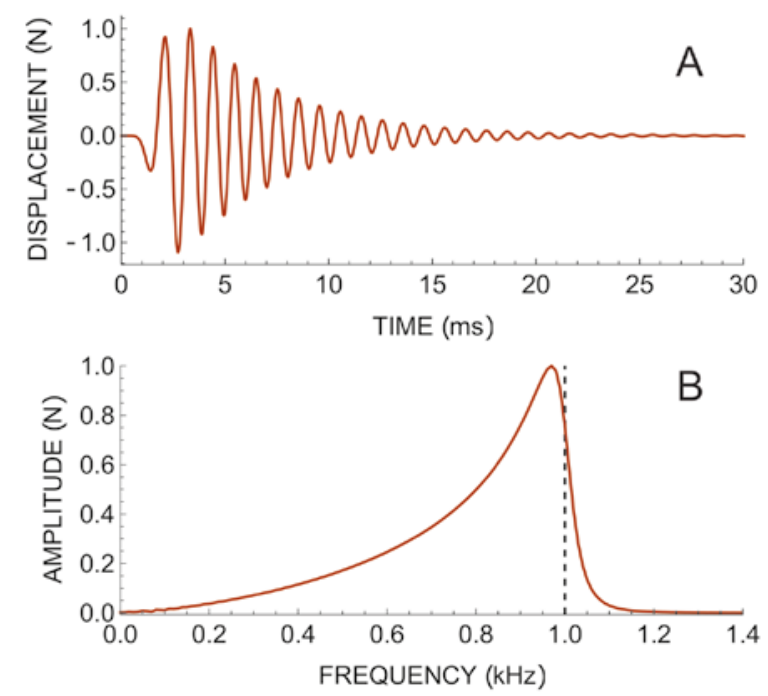

Figure 4. A. Displacement of oscillator 284 as a function of time, if the first oscillator in the array is stimulated with a very short impulse. $B$. The amplitude spectrum of the signal in $\mathrm{A}$

velocity 0 . Natural frequencies $f_{\mathrm{j}}$ decayed exponentially from 20 to $0.1 \mathrm{kHz}$ for $n=2, \ldots, 501$. Damping factor $\gamma_{j}$ was 0.07 for all $j$, except for oscillator 1 , where it was 1.0. The natural frequency of the first oscillator in the array was set at $2.5 \mathrm{kHz}$. This oscillator is a (simplified) representation of the middle ear, including the tympanic membrane.

Results of solving the set of differential equations are shown in Figure 3. After a few initial periods all oscillators, up to about number 290, move sinusoidally with a frequency of $1 \mathrm{kHz}$ (Figure 3A), but with different amplitudes (Figures $3 \mathrm{~A}$ and $\mathrm{B}$ ). Amplitudes gradually increase with increasing oscillator number up to oscillator 280 (natural frequency $1.05 \mathrm{kHz}$ ), after which it rather abruptly decreases to zero. The phase delay also increases with increasing oscillator number, up to more than two periods before the amplitude suddenly drops, as can be derived from the curvature of the ridges of maximum (coloured red) or minimum (coloured blue) displacement in Figure 3A.

Figure $3 \mathrm{C}$, calculated in the same way as the envelope in Figure $3 \mathrm{~B}$, but now for amplitudes on a logarithmic (dB) scale, can be compared with results obtained 70 years ago by Bogert [18; Figure 8] with a hardware transmission line model consisting of 175 sections, or with Figure 3.3 in the book on cochlear mechanics by Duifhuis [19].

\section{Click stimulus}

The sine wave stimulus for oscillator 1 was replaced by a very short gaussian pulse (FWHM $5 \mu \mathrm{s}$ ), acting as a click stimulus. The set of 501 differential equations was again solved for the same set of parameters. Now the response of all oscillators is a decaying waveform, with an onset delay and an increasing instantaneous frequency (decreasing time between zero-crossings) during the first periods. This is illustrated in Figure 4, showing the response of oscillator 284 (natural frequency $1 \mathrm{kHz}$ ), together with its amplitude spectrum. 


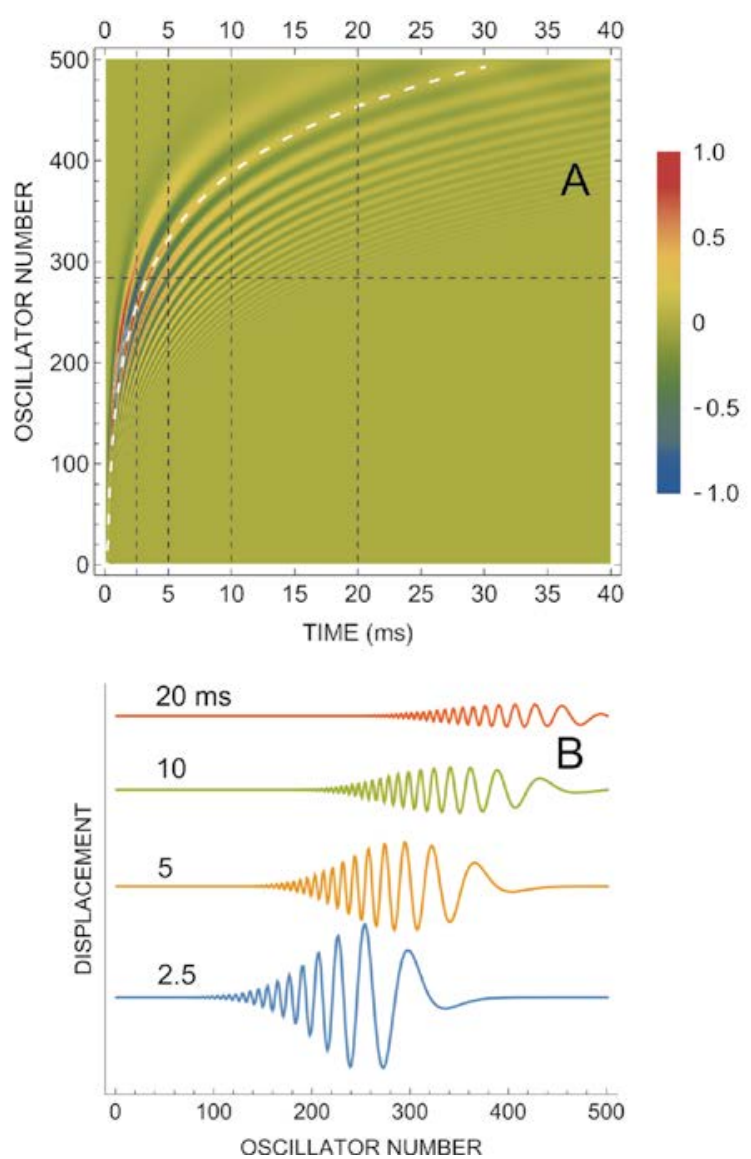

Figure 5. A. Density plot of the response of all oscillators in response to a click, as a function of time. The horizontal dashed line marks the position of oscillator 284, with natural frequency $1 \mathrm{kHz}$. The vertical dashed lines mark the positions of the displacement profiles shown in B. The dashed white line follows a local maximum of the displacement profile. B. Displacement profiles at 2.5, 5, 10, and $20 \mathrm{~ms}$ after presentation of a $5 \mu$ s pulse to oscillator 1
Figure $5 \mathrm{~A}$ is a density plot showing the response of all oscillators in the array to the click stimulus. A section along the horizontal dashed gridline in this figure gives the response of oscillator 284, as shown in Figure 4A. Sections along the vertical gridlines give the displacement profiles of the array at successive times, as shown in Figure $5 \mathrm{~B}$. The profile hardly changes shape (apart from its magnitude) while travelling along the array towards its low frequency end.

The displacement profile in Figure 5B slows down while it travels along the array: after the click stimulus is presented it covers the same distance between 2.5 and $5 \mathrm{~ms}$ as between 10 and $20 \mathrm{~ms}$. The velocity of the displacement profile can more precisely be derived from the slope of the dashed white line in Figure 5A, giving the result that this velocity decreases exponentially from $40 \mathrm{~mm} / \mathrm{ms}$ at the high frequency end to almost zero at the low frequency end.

\section{One irregularity}

The natural frequency of oscillator 284 was multiplied with 1.02 , changing its natural frequency from $1 \mathrm{kHz}$ to $1.02 \mathrm{kHz}$. In this way a single irregularity is created in the array of oscillators. The responses of the array to a $5 \mu \mathrm{s}$ pulse, applied to oscillator 1 , were again calculated, for the same set of parameters as before. The response of the (heavily damped) oscillator 1 is given in Figure 6A, and with an expanded vertical scale in Figure 6B. For comparison the same responses are shown in Figures $6 \mathrm{C}$ and $\mathrm{D}$, calculated for the situation that no irregularity is present in the oscillator array.

The oscillatory component between 3 and $30 \mathrm{~ms}$ in Figure $6 \mathrm{~B}$ is not present in Figure 6D. This extra component is created by an extra component in the pressures $p_{\mathrm{j}}$ that drive the oscillators (see Equation 1). It is the result of the presence of the irregularity in the oscillator array.
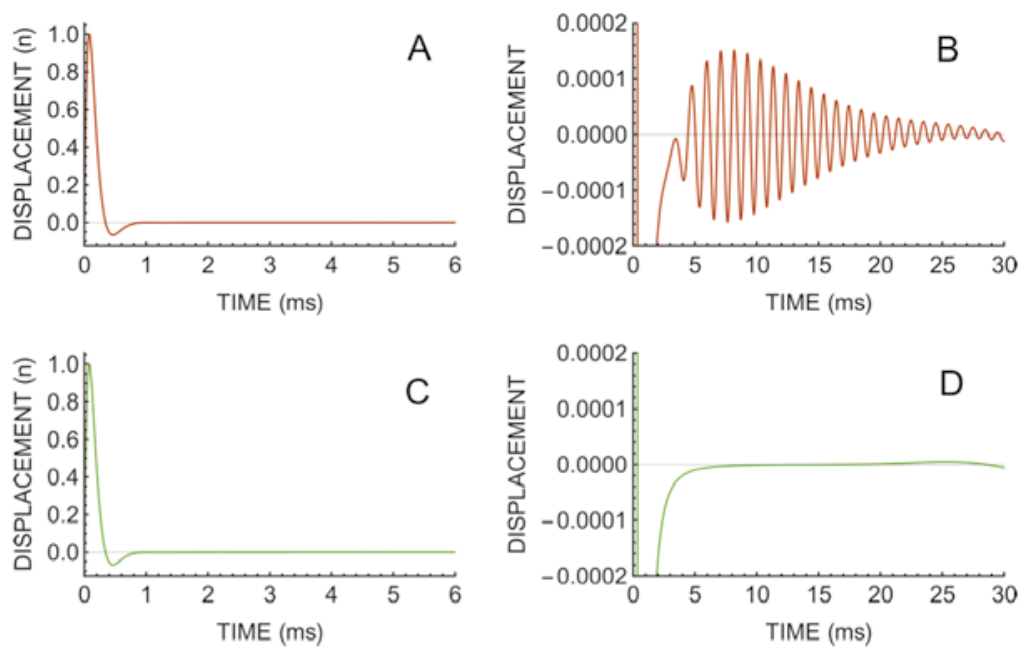

Figure 6. A and B. Displacement of oscillator 1 as a function of time with different scales, evoked by a $5 \mu$ s pulse applied to this oscillator, after introduction of a small irregularity at the position of oscillator 284. C and D. Same as A and B, but now without an irregularity being present in the array 


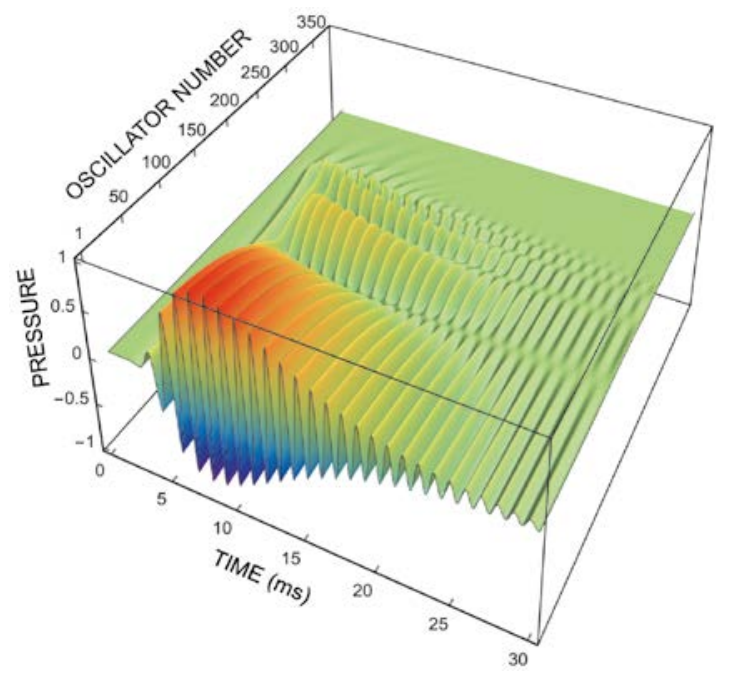

Figure 7. Extra pressure component (with normalised maximum value), created by a single irregularity at the position of oscillator 284

The array of fluid pressures $\boldsymbol{p}(t)$ (see Equation 2 in Appendix 1) was calculated, both for the situation with and without irregularity at the position of oscillator 284, together with their difference. This difference, being the extra (weak) pressure component created by the presence of the irregularity, is shown in Figure 7.

The pressure component shown in Figure 7 is presented as a density plot in Figure 8A. The horizontal dashed line in this figure marks oscillator 284, where the irregularity is. Figure $8 \mathrm{~B}$ is the pressure profile along the array at $t=15.35 \mathrm{~ms}$, marked with the vertical dashed line in Figure $8 \mathrm{~A}$. Figure $8 \mathrm{C}$ shows 11 successive profiles along this dashed line for $t=15.35,15.40,15.45, \ldots, 15.85 \mathrm{~ms}$, covering half a period of the pressure oscillation.
It is clear from Figures 7 and 8 that the irregularity creates a standing wave pattern between oscillators 284 and 1 , with sharp nodes at the positions of oscillators 155,230 , and 264. The standing wave is the sum of waves that travel backward and forward between the discontinuity, where they are reflected, and oscillator 1 . That the distance between the nodes in Figure 8C decreases with increasing oscillator number is the result of the decreasing velocity for the displacement profile (see Figure 5). The relation between velocity and node distance is explained in Appendix 2.

\section{Irregular array}

Now the natural frequencies of all oscillators (except oscillator 1 ) were multiplied by $1+\delta_{\mathrm{j}}$, where $\delta_{\mathrm{j}}$ is randomly taken from a normal distribution with mean 0 and standard deviation 0.02. The result is shown in Figure 9A for part of the oscillator array.

The calculation, in the same way as for the case with only one irregularity, was repeated. This gave the displacement of oscillator 1 as shown in Figure 9B, after suppression of the first $1.5 \mathrm{~ms}$ to remove the much stronger short initial response that is shown in Figures 6A and C. This is the impulse response for oscillator 1, being the response of the middle ear and hence the signal in the ear canal, that is measured as a CEOAE in clinical practice. The amplitude spectrum for the signal in Figure 9B is given in Figure 9C. It is irregular, and the strongest frequency components are roughly in the range $0.5-4 \mathrm{kHz}$.

A wavelet time-frequency analysis was performed on the signal in Figure 9B. This analysis was identical to the method used by Wit et al. [25], with one exception: the asymmetrical gammatone wavelet was replaced by a symmetrical gaussian wavelet which was adjusted to obtain the same resolution in the time and frequency domains. The result of the analysis is a $50 \times 50$ array of values for the amplitude of the analysed signal in the time-frequency plane.
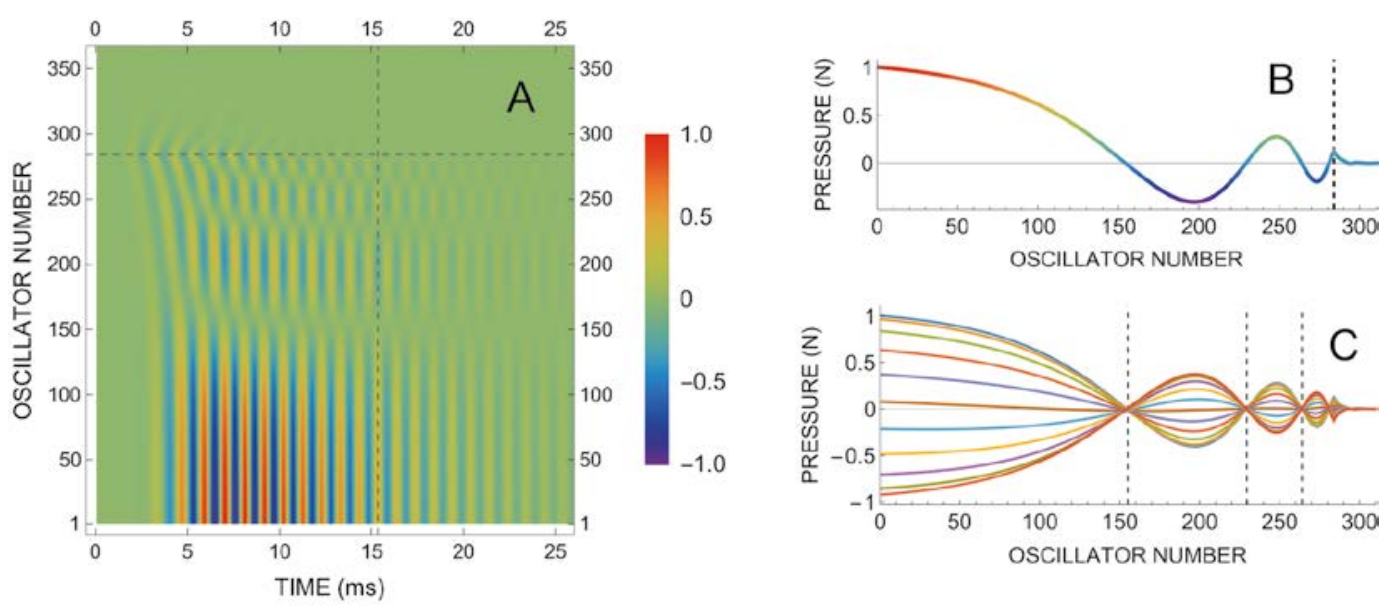

Figure 8. A. Density plot for the pressure profile. The colour bar gives pressure. The horizontal dashed line is at the position of the irregularity in the oscillator array. B. Pressure profile at $t=15.35 \mathrm{~ms}$, along the vertical dashed line in A. C. Successive pressure profiles for half a period of the pressure oscillation starting at $t=15.35 \mathrm{~ms}$. The dashed lines are at oscillator numbers 155,230 , and 264 , being the positions of the nodes of the standing wave 

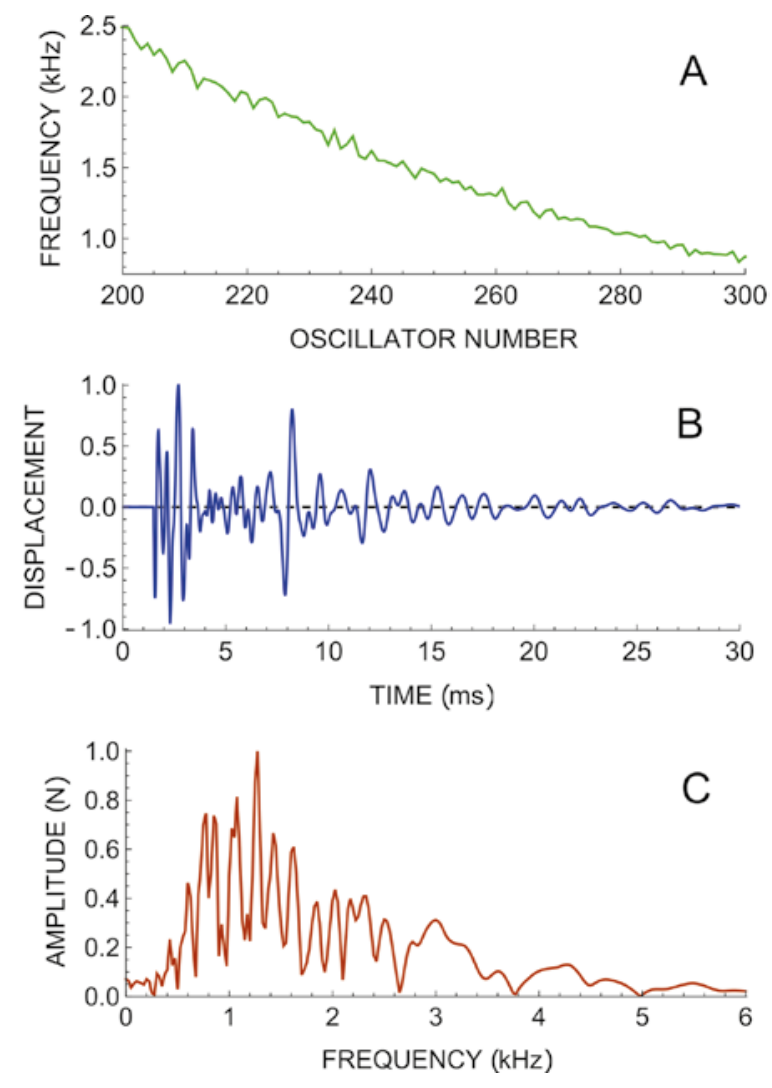

Figure 9. A. Detail of frequency versus oscillator number relation. B. Displacement of oscillator 1 as a function of time (the first $1.5 \mathrm{~ms}$ is suppressed, to remove the much stronger impulse response of oscillator 1, as shown in Figure 6A). C. Amplitude spectrum for the signal in B

Details of the method can be found in [25]. The result of the analysis of the signal in Figure 9B is given in Figure 10A.

The procedure to obtain Figures 9 and 10A was repeated for an a new generated array of random irregularities $\delta_{j}$, giving Figure 10B.

The procedure to obtain Figures 10A and B was repeated, each time with a newly generated set of irregularities, until 100 time-frequency arrays were obtained. The average of this set of $50 \times 50$ arrays is shown in Figure 11, both in a 3-D plot and in a density plot. Figure $11 \mathrm{~B}$ should for instance be compared with Figure 2A in [26], being average time-frequency distributions of CEOAE amplitude from 26 normal ears.

\section{Discussion}

\section{CEOAE as sum of gammachirps}

If the signal in Figure $6 \mathrm{D}$ is subtracted from that in Figure $6 \mathrm{~B}$, the extra component in the impulse response of oscillator 1 is obtained. This extra component is evoked by the introduction of an irregularity at the position of oscillator

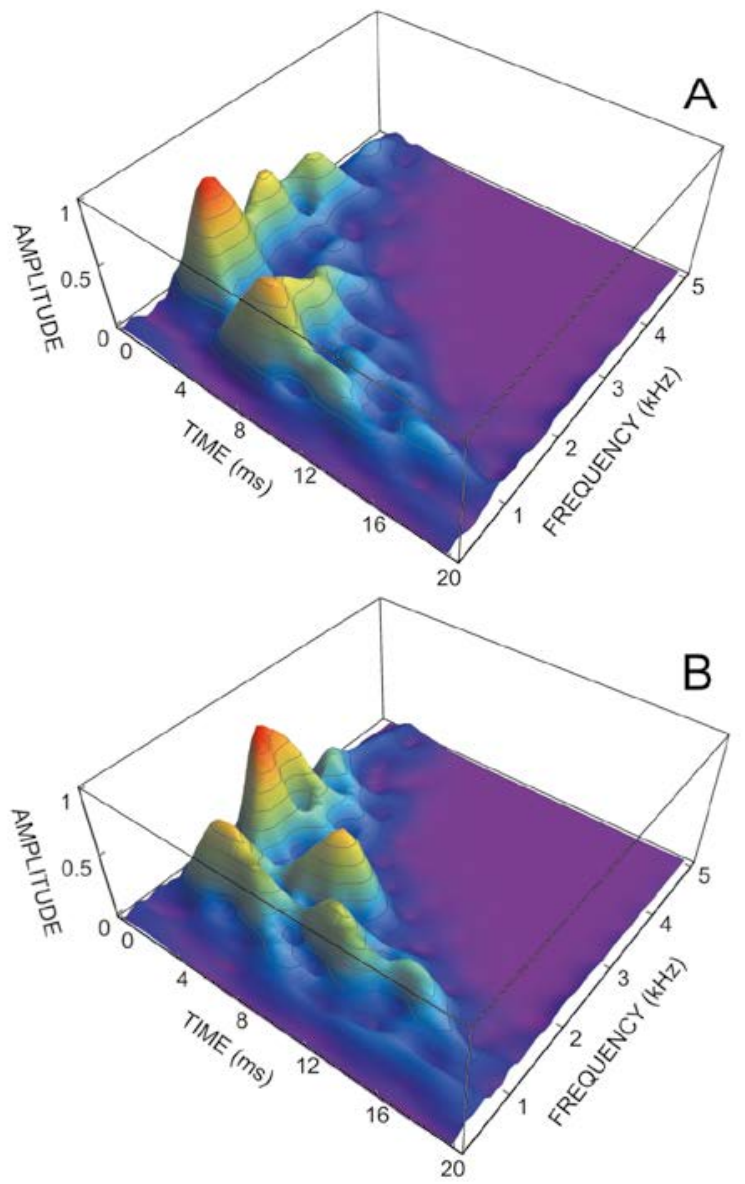

Figure 10. A. Time-frequency analysis of the signal shown in Figure 9B. B. The same, but for another array of irregularities

284 (natural frequency $1 \mathrm{kHz}$ ). It is shown as the solid line in Figure 12A, after removal of a short onset delay, together with its amplitude spectrum in Figure 12C. The signal has the shape of a gammachirp, and can be reasonably well fitted with a gammachirp of order 3.5 , as shown with the dotted line. Apparently, a discontinuity at the position in the array of the oscillator with natural frequency $1 \mathrm{kHz}$ produces a standing wave pattern between the discontinuity and oscillator 1 (see Figures 7 and 8), with a main frequency of $1 \mathrm{kHz}$.

If the single discontinuity in oscillator 284 is replaced by one in oscillator 219 , with natural frequency $2 \mathrm{kHz}$, a comparable result - but now with a frequency of $2 \mathrm{kHz}-$ is obtained, as can be seen in Figures 12B and D.

So, in the present model a CEOAE is the sum of gammachirps, and such a sum is shown in Figure 9B. Timefrequency analyses of the sum of gammachirps produce different results for different "ears" (arrays of irregularities), and do not differ from those of real CEOAEs (Figures 10 and 11). In this respect it is not surprising that the earlier "sum of gammatones" approach [13] gave a rather good reproduction of a CEOAE. 

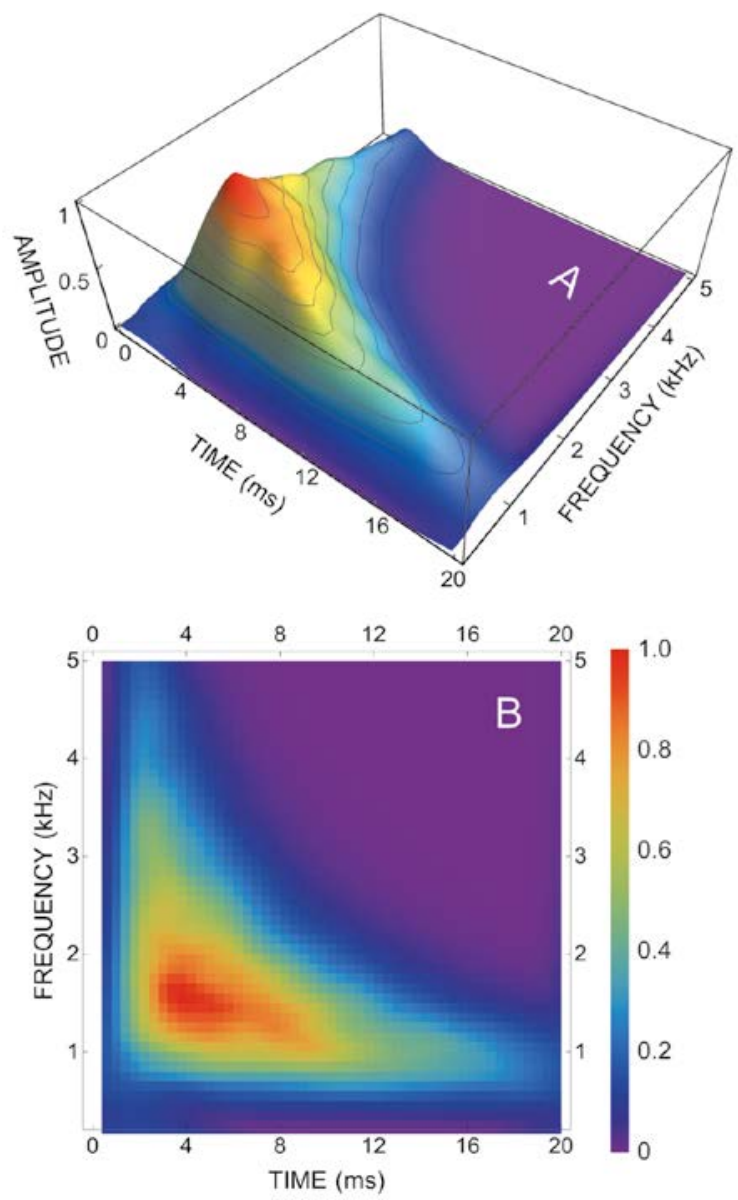

Figure 11. A. 3D-plot for the normalised average of 100 time-frequency plots, like those in Figures $10 \mathrm{~A}$ and $\mathrm{B}$. $B$. The same average, but now shown as a density plot of the $50 \times 50$ array of amplitude values
A consequence of the present model is that no two ears can have the same pattern of irregularities along the cochlear partition, because no two ears produce exactly the same CEOAE [11]. The oscillators in the model by Fruth et al. [27], describing the statistics of spontaneous otoacoustic emissions, are - for a comparable reason - subject to a weak spatial disorder "that lends individuality to the simulated cochlea".

\section{Frequency glides}

If the oscillators in Figure 2 were not coupled, their impulse response would be that for an isolated, weakly damped, harmonic oscillator, being an exponentially decaying oscillation with a constant frequency. Cochlear impulse responses, as for instance those measured by De Boer and Nuttall [28] with a laser Doppler vibrometer, do not have a constant frequency. They show a distinct frequency glide: an initial increase in instantaneous frequency, which levels off after several cycles to a constant value (the characteristic frequency).

Shera [29] argued that upward frequency glides in click responses of the basilar membrane (as measured at a particular point) originate primarily through the time dependence of the fluid pressure at that point - a global effect which is not compatible with the differential build-up and decay of multiple micromechanical resonances at that location (as some earlier models had supposed).

The present model supports Shera's view straightforwardly: the only coupling between the oscillators in the model used here is through the pressure of the fluid that surrounds the oscillators (see Figure 2), as represented by Equation 2 in Appendix 1. And - as can be seen in Figure 4A - this coupling produces an initial frequency glide (decreasing time between zero-crossings) in the impulse response of the oscillators in the array.
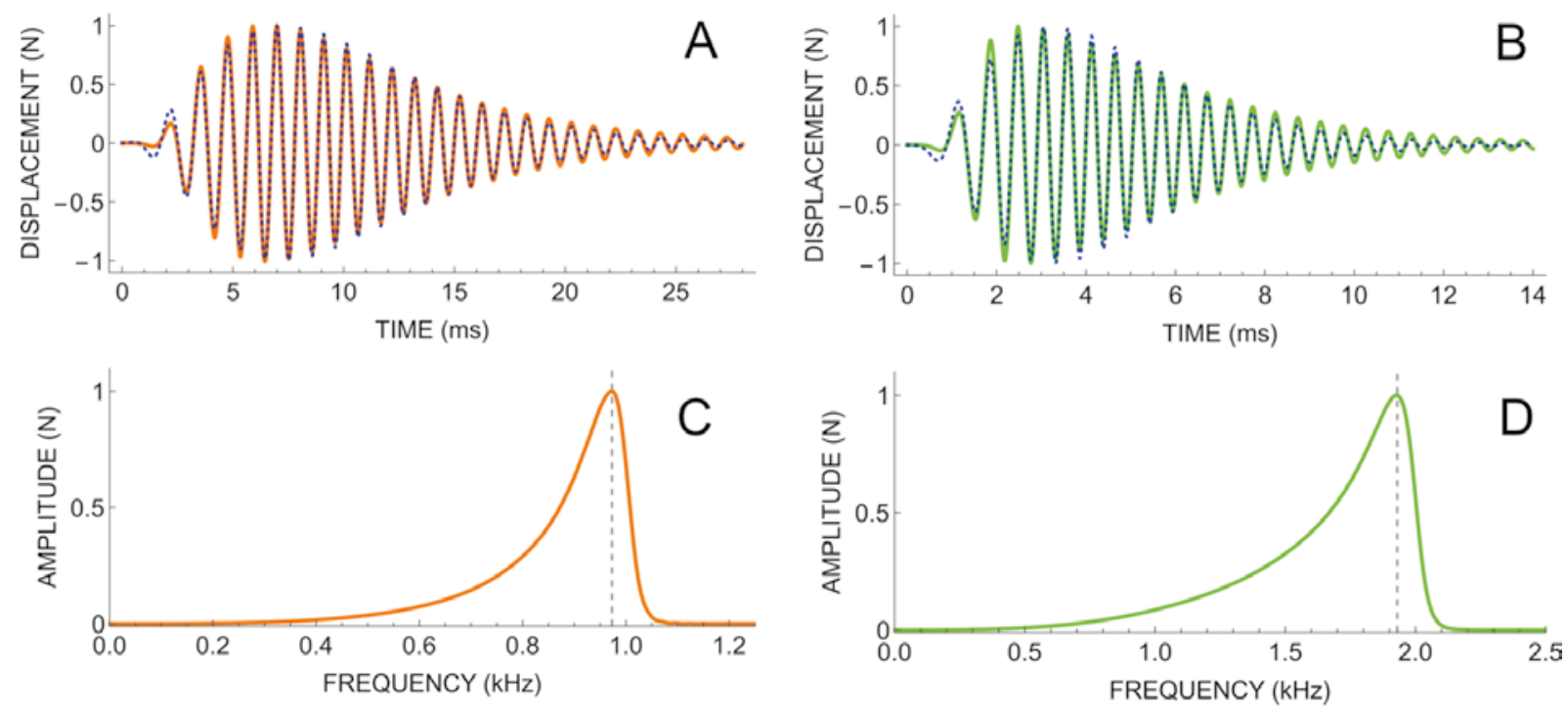

Figure 12. A, B. Solid lines: Extra component in the impulse response of oscillator 1, evoked by the introduction of an irregularity at the positions of the oscillators with natural frequencies 1 and $2 \mathrm{kHz}$ respectively. Dotted lines: fits with a gammachirp of order 3.5, with equation $d(f, t)=a t^{2.5} e^{-b t} \sin \left[2 \pi f\left(t+a e^{-t / \mu}-a\right)+\varphi\right.$ ] (see Appendix 3 for an elucidation of the equation). C, D. Amplitude spectra for the signals shown with a solid line in A and B 


\section{Conclusion}

In the "sum of gammatones" approach $[13,14]$ it is supposed that the gammatones are the locally generated impulse responses of cochlear oscillators. And, if the place-frequency map of the cochlea is irregular, then these impulse responses are transported back to the ear canal without delay and add up to a CEOAE-like signal.

In the present paper a CEOAE is the sum of gammachirps created by repeated reflection of a travelling wave at irregularities in the place-frequency map. This creates a standing wave pattern in the cochlear fluid pressure, being the sum of waves travelling back and forth repeatedly between the irregularities in the array and the stapes. If irregularities are present all along the array, the gammachirps add up to a signal with the same characteristics as a CEOAE measured in a normal hearing ear.

\section{Appendix 1}

The state space model [22-24] adopts the long wavelength assumption, with as a starting point the differential equation $\left[\delta^{2} p(t) / \delta x^{2}\right]-\left[2 \rho \delta^{2} w(t) / H \delta t^{2}\right]=0$. This equation describes the one-dimensional "slow" wave propagation along the cochlea $[19,22]$. The waveform of the differential pressure along the cochlear partition is given by $p(t) ; \delta^{2} w(t) / \delta t^{2}$ is the radially averaged transverse acceleration of the cochlear partition; $\rho$ is the density of the cochlear fluid; and $H$ is the height of the canal above and below the cochlear partition, which is assumed to be constant. For a cochlea with discrete sections of length $\Delta$, the term $\delta^{2} p(t) / \delta \mathrm{x}^{2}$ is, for the $j$-th section, approximated by $\left[p_{\mathrm{j}-1}(t)-2 p_{\mathrm{j}}(t)+p_{\mathrm{j}+1}(t)\right] / \Delta^{2}$.

Following Equations 10 and 11 in Elliott et al. [22], the relation between the array of $n$ local pressures $\boldsymbol{p}(t)$ and the array of $n$ accelerations $\boldsymbol{a}(t)$ will be given by $\boldsymbol{F} \cdot \boldsymbol{p}(t)=\alpha \boldsymbol{a}(t)$ in which $\boldsymbol{F}$ is an $n \times n$ finite difference matrix and $\alpha$ a multiplication factor proportional to fluid density $\rho$. Furthermore, $\boldsymbol{p}(t)=\left\{p_{1}(t), p_{2}(t), \ldots p_{\mathrm{n}}(t)\right\}^{T}$, and $\boldsymbol{a}(t)=\left\{a_{1}(t)\right.$, $\left.a_{2}(t), \ldots a_{\mathrm{n}}(t)\right\}^{T}$, with $a_{\mathrm{j}}(t)=\ddot{x}_{\mathrm{j}}(t)$.

The $j$-th row of matrix $F$ is $\{0,0, \ldots, 1,-2,1,0,0, \ldots, 0)$, where -2 is the diagonal element. The consequence is that the $j$-th element in the product $\boldsymbol{F} \cdot \boldsymbol{p}(t)$ is $p_{\mathrm{j}-1}(t)-2 p_{\mathrm{j}}(t)+p_{\mathrm{j}+1}(t)$, being the numerator in the expression above that approximates $\delta^{2} p(t) / \delta x^{2}$. Multiplication of both sides of $\boldsymbol{F} \cdot \boldsymbol{p}(t)=\alpha \boldsymbol{a}(t)$ with the inverse matrix $\boldsymbol{F}^{-1}$ gives

$\boldsymbol{p}(t)=\alpha \boldsymbol{F}^{-1} \cdot \boldsymbol{a}(t)$.

According to equation (2), local pressure $p_{\mathrm{j}}(t)$ in Equation 1 in the model section above will now be given by $\alpha \sum_{i=1}^{n-1} F^{-1}(j, i) \times \ddot{x}_{\mathrm{i}}(t)$, with $F^{-1}(j, i)$ being the $i$-th element of the $j$-th row of $\boldsymbol{F}^{-1}$, and $\ddot{x}_{\mathrm{i}}(t)$ the acceleration of oscillator $i$ at time $t$. With this relation for $p_{\mathrm{j}}(t)$, Equation $1 \mathrm{spec}-$ ifies the instantaneous response of the $j$-th oscillator to the pressure set up at that point by the motion (and fluid displacement) of all the other oscillators. The structure of matrix $F^{-1}$ is illustrated in Figure 4 in [23], showing that the accelerations of the oscillators with a natural frequency higher than $f_{j}=\omega_{j} / 2 \pi$ (the oscillators situated more basal) contribute equally strongly to the pressure exerted on the $j$-th oscillator, while the contribution of the more apical oscillators decreases linearly with decreasing natural frequency.

The value of differential fluid pressure parameter $\alpha$ in Equation 2 is given by the value of $2 \rho \Delta^{2} / h$ in the state space model [22], where $\Delta$ is the length of one basilar membrane section, $h$ the height of the fluid canal above and below the cochlear partition, and $\rho$ the density of the fluid. The values used for $\Delta, h$, and $\rho$ in the "statespace example.m" Matlab-file are $35 / 512 \times 10^{-3} \mathrm{~m}(35 \mathrm{~mm}$ divided into $512 \mathrm{sec}$ tions), (units of $10^{-3} \mathrm{~m}$ and $10^{3} \mathrm{~kg} / \mathrm{m}^{3}$ respectively), giving the value 0.00935 for $2 \rho \Delta^{2} / h$. This was rounded off to 0.01 as the value of $\alpha$.

\section{Appendix 2}

To describe the standing wave pattern, that can be seen in Figures 7 and 8 , we start with $d_{\mathrm{b}}(x, t)=\sin [2 \pi(f t+c x)]$, being a sinusoidal wave, travelling backward along the oscillator array with constant velocity ( $x$ is oscillator number, $t$ is time, $f$ is frequency, $c$ is a constant). If a forward travelling wave $d_{\mathrm{f}}(x, t)=\sin [2 \pi(f t-c x)]$, also with constant velocity, is added to the backward travelling wave, a standing wave $d_{\mathrm{s}}(x, t)=d_{\mathrm{b}}(x, t)+d_{\mathrm{f}}(x, t)$ is obtained. This sum can also be written as $d_{\mathrm{s}}(x, t)=2 \sin [2 \pi \mathrm{ft}] \cos [2 \pi \mathrm{cx}]$, from which it can be concluded that the nodes of the standing wave are at the zero-crossings of the cosine term. These zerocrossings are at the solution of $2 \pi \mathrm{cx}=\pi(2 n-1) / 2 ; n=1,2$, $\ldots$; being $x=(2 n-1) / 4 c$. The wavelength of the standing wave, the distance between successive odd or even numbered nodes, is then given by $\lambda=1 / c$.

It is clear at a glance that the standing wave in Figure 8C does not have a constant wavelength. The term $\cos [2 \pi \mathrm{cx}]$ in the above formula for the standing wave is therefore replaced by $\cos [2 \pi \varphi(x)]$. To give the positions of the nodes in Figure 8C, marked with the dashed lines, $\varphi(x)$ must then have the values $1 / 4,3 / 4,5 / 4$ for $x=155,230,264$ respectively. This condition is represented with the red dots in Figure A below. The blue line in the same figure is a fit with $\varphi(x)=\alpha\left(e^{\beta x}-1\right)$, for $\alpha=0.03016$ and $\beta=0.01419$. Figure $B$ gives $\cos \left[2 \pi \alpha\left(e^{\beta x}-1\right)\right]$ for these values of $\alpha$ and $\beta$.
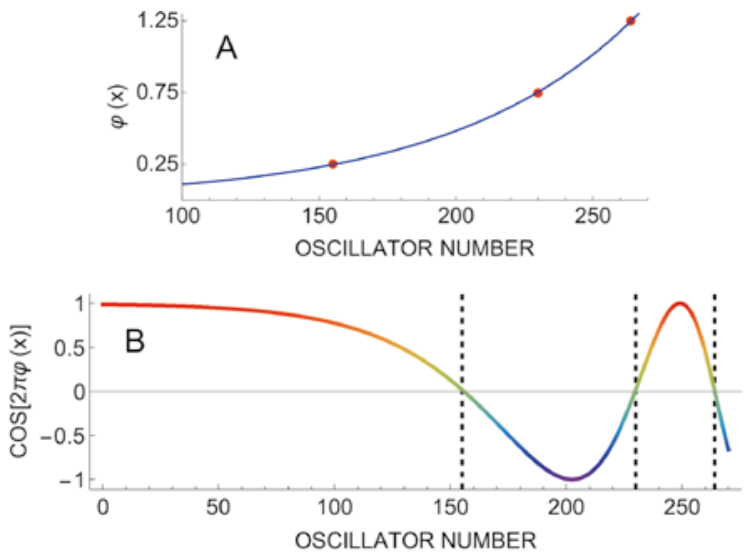

\section{Appendix 3}

A convenient formula for the initial frequency glide (if present) of an impulse response is: $f(t)=f_{\infty}\left(1-\rho e^{-t / \mu}\right)$, with $f(t)$ 
being the instantaneous frequency as a function of time $t$, $f_{\infty}$ the final frequency, $\rho$ determines $f(0)$, and $\mu$ represents how fast $f(t)$ reaches its final value. The time integral of $f(t)$ is $f_{\infty}\left(t+\rho \mu e^{-t / \mu}\right)$. From this integral a formula for the oscillating term of an impulse response can be derived: $O(t)=\sin \left[2 \pi f_{\infty}\left(t+\rho \mu \mathrm{e}^{-t / \mu}-\rho \mu\right)+\varphi_{0}\right]$. (The term $-\rho \mu$ was added to make the oscillating term start at zero, for initial phase $\varphi_{0}=0$.) A formula for a gammachirp of order $n$ is obtained by multiplying $O(t)$ with the envelope function $\alpha t^{n-1} e^{-b t}$, giving $d(f, t)=\alpha t^{2.5} e^{-b t} \sin \left[2 \pi f\left(t+\alpha e^{-t / \mu}-\alpha\right)+\varphi\right]$, for $n=3.5$.

The generally used equation for a gammachirp is [30]: $g(t)=\alpha t^{n-1} e^{-b t} \cos \left[2 \pi f_{\infty} t-c \log t+\varphi\right]$.
In this case the instantaneous frequency of $g(t)$ is obtained by differentiating $2 \pi f_{\infty} t-c \log t+\varphi$ with respect to $t$, and dividing the result by $2 \pi$, giving $f(t)=f_{\infty}-\frac{c}{2 \pi t}$ for the instantaneous frequency as a function of time. In this equation there is only one parameter $(c)$ to determine the profile of the initial frequency change, while in $d(f, t)$ this profile is determined by two parameters $(\rho$ and $\mu$ ).

Furthermore: $f(t)$ is negative for $t<\frac{c}{2 \pi f_{\infty}}$ (for positive $c$, to have an increasing instantaneous frequency). And if $t$ approaches 0 for positive $t$, the oscillating term $\cos \left[2 \pi f_{\infty} t-c \log t+\varphi\right]$ will show an irregular behaviour, depending on the value of $c$. It is unlikely that a physically realisable oscillating system would show such behaviour.

\section{References}

1. Kemp DT. Active resonance systems in audition. 13th International Congress of Audiology, Bari, Italy, 1976; Abstracts 64-5.

2. Kemp DT. Stimulated acoustic emissions from within the human auditory system. J Acoust Soc Am, 1978; 64: 1386-91.

3. Wit HP, Ritsma RJ. Stimulated emissions from the human ear. J Acoust Soc Am, 1979; 66: 911-13.

4. Wit HP, Ritsma RJ. Evoked responses from the human ear: Some experimental results. Hear Res, 1980: 2: 253-61.

5. Rutten WLC. Evoked acoustic emissions from within normal and abnormal human ears: comparison with audiometric and electrocochleographic findings. Hear Res, 1980; 2: 263-71.

6. Schloth E. Amplitudengang der im äuszeren Gehörgang gemessenen akustischen Antworten auf Schallreize. Acustica, 1980; 44: 239-41.

7. Wilson JP. Evidence for cochlear origin for acoustic re-emissions, threshold fine-structure and tonal tinnitus. Hear Res, 1980; 2: 233-52.

8. Probst R, Lonsbury-Martin BL, Martin GK. A review of otoacoustic emissions. J Acoust Soc Am, 1991; 89: 2027-67.

9. Kemp DT. Otoacoustic emissions, their origin in cochlear function, and use. Brit Med Bull, 2002; 63: 223-41.

10. Kemp DT, Chum R. Properties of the generator of stimulated acoustic emissions. Hear Res, 1980: 2: 213-32.

11. McFadden D, Loehlin JC, Pasanen, EG. Additional findings on heritability and prenatal masculinization of cochlear mechanisms: click-evoked otoacoustic emissions. Hear Res, 1996:97:102-19.

12. Zweig G, Shera CA. The origin of periodicity in the spectrum of evoked otoacoustic emissions. J Acoust Soc Am, 1995; 98: 2018-47.

13. Wit HP, van Dijk P, Avan P. Wavelet analysis of real ear and synthesized click evoked otoacoustic emissions. Hear Res, 1994; 73: 141-7.

14. Wit HP, van Dijk P, Avan P. On the shape of (evoked) otoacoustic emission spectra. Hear Res, 1994; 81: 208-14.

15. Gold T. Hearing II. The physical basis of the action of the cochlea. Proc Roy Soc B, 1948; 135: 492-8.

16. Gold T. Historical background to the proposal, 40 years ago, of an active model for cochlear frequency analysis. In: JP Wilson, DT Kemp (eds). Cochlear mechanisms, structure, function and models. Plenum Press, New York, 1988: 299-305.
17. Sutton GJ, Wilson JP. Modelling cochlear echoes: the influence of irregularities in frequency mapping and summed cochlear activity. In: E de Boer, MA Viergever (eds) Mechanics of Hearing. Delft University Press, Delft, 1983: 83-90.

18. Bogert BP. Determination of the effects of dissipation in the cochlear partition by means of a network representing the basilar membrane. J Acoust. Soc. Am, 1951; 23: 151-4.

19. Duifhuis H. Cochlear Mechanics: An introduction to time domain analysis of the nonlinear cochlea. Springer, 2012.

20. Moleti A, Al-Maamury AM, Bertacci D, Botti T, Sisto, R. Generation of the long- and short-latency components of transientevoked otoacoustic emissions in a nonlinear cochlear model. J Acoust Soc Am, 2013; 133: 4098-108.

21. Laubenbacher R, Pareigis B. Equivalence relations on finite dynamical systems. Adv Appl Math, 2001; 26(3): 237-51.

22. Elliott SJ, Ku EM, Lineton B. A state space model for cochlear mechanics. J Acoust Soc Am, 2007; 122: 2759-71.

23. Elliott SJ, Lineton B, Ni G. Fluid coupling in a discrete model of cochlear mechanics. J Acoust Soc Am, 2011; 130: 1441-51.

24. Elliott SJ, Ni G. An elemental approach to modelling the mechanics of the cochlea. Hear Res, 2018; 360: 14-24.

25. Geven LI, Wit HP, de Kleine E, van Dijk P. Wavelet analysis demonstrates no abnormality in contralateral suppression of otoacoustic emissions in tinnitus patients. Hear Res, 2012; 286: 30-40.

26. Jedrzejczak WW, Bell A, Skarzynski PH, Kochanek K, Skarzynski H. Time-frequency analysis of linear and nonlinear otoacoustic emissions and removal of a short-latency stimulus artefact. J Acoust Soc Am, 2012; 131: 2200-8.

27. Fruth F, Jülicher F, Lindner B. An active oscillator model describes the statistics of spontaneous otoacoustic emissions. Biophys J, 2014; 107: 815-24.

28. De Boer E, Nuttall AL. The mechanical waveform of the basilar membrane. I. Frequency modulations ("glides") in impulse responses and cross-correlation functions. J Acoust Soc Am, 1997; 101: 3583-92.

29. Shera CA. Frequency glides in click responses of the basilar membrane and auditory nerve: their scaling behavior and origin in travelling wave dispersion. J Acoust Soc Am, 2001; 109: 2023-34.

30. Irino T, Patterson RP. A time-domain, level-dependent auditory filter: the gammachirp. J Acoust Soc Am, 1997; 101: 412-9. 